\title{
Quantifying land fragmentation metrics for cattle enterprises in Northern Ireland
}

\author{
Georgina Milne', Andrew Byrne'2, Emma Campbell'1, Jordon Graham¹, John McGrath ${ }^{3}$, Raymond \\ Kirke $^{4}$, Wilma McMaster ${ }^{5}$, Jesko Zimmermann ${ }^{5}$ and Adewale Henry Adenuga ${ }^{1}$
}

1. Agri-food and Biosciences Institute (AFBI), Belfast BT4 3SD, UK;

2. One-Health Unit, Department of Agriculture, Food and the Marine, Agriculture House, Dublin, Ireland;

3. Department of Agriculture, Environment and Rural Affairs (Area Based Scheme), Orchard House, Foyle Street, Derry/Londonderry, BT48 6AT;

4. Department of Agriculture, Environment and Rural Affairs (Veterinary Service Animal Health), Ballykelly House, Ballykelly Road. Ballykelly. Limavady. BT49 9HP; 5. Department of Agriculture, Environment and Rural Affairs (Land Parcel Identification System), Dundonald House, Belfast, BT4 3SB, UK;

6. Department of Agrifood Business and Spatial Analysis, Rural Economy \& Development Programme, Teagasc, Ashtown Research Centre, Dublin 15, Ireland.

* Correspondence: georgina.milne@afbini.gov.uk

\begin{abstract}
Farm fragmentation is the occurrence of numerous and often discontinuous land parcels associated with a single farm. Farm fragmentation is considered to be a defining feature of Northern Ireland's (NI) agricultural landscape, influencing agricultural efficiency, productivity, and the spread of livestock diseases. Despite this, the full extent of farm fragmentation in cattle farms is not well understood, and little is known of how farm fragmentation either influences, or is influenced by, different animal production types. This study describes and quantifies farm fragmentation metrics for cattle enterprises in NI, presented separately for dairy and non-dairy production types. We find that $35 \%$ of farms consist of five or more fragments, with larger farms associated with greater levels of farm fragmentation, fragment dispersal and contact with contiguous farms. Moreover, this was particularly evident in dairy farms, which were over twice the size of farms associated with non-dairy production types, with twice as many individual land parcels and twice as many fragments. We hypothesise that the difference in farm fragmentation and farm size between dairy and non-dairy production types is associated with the recent expansion of dairy farms after the abolition of the milk quota system in 2015, which may have driven the expansion of dairy farms via the acquisition of land. The high levels of land fragmentation, fragment dispersal and contiguous contact observed in NI cattle farms may also have important implications for agricultural productivity and epidemiology alike. Whilst highly connected pastures could facilitate the dissemination of disease, highly fragmented and parcellised land could also hamper productivity via diseconomies of scale, such as preventing the increase of herd sizes or additionally, adding to farm costs by increasing the complexity of herd management.
\end{abstract}

Keywords: Farm fragmentation; Land fragmentation; cattle farming; agricultural productivity; Northern Ireland;

\section{Introduction}

In the literature, the term land fragmentation has been conceptualized in different ways depending on the context in which it is defined. For Bentley (1987), land fragmentation is simply the scattering of farmland. Whereas, King and Burton (1982) defines it as a basic rural 
spatial issue, whereby farms are imperfectly organized at separate locations across an area. More recently, farmland fragmentation has been defined as the process whereby farming households possess a number of non-contiguous land plots, scattered over a wide range of area and defined by spatial characteristics such as farm size, the size and shape of land parcels, the number of land parcels belonging to the farm, the size distribution of plots and the spatial distribution of plots (Sundqvist and Andersson, 2007; Sklenicka et al., 2014; de Vries, 2016; Ntihinyurwa et al., 2019). In this respect, farmland fragmentation can be viewed as a multidimensional phenomenon defined in terms of physical fragmentation (use, shape, value, and location), tenure fragmentation (both visible and hidden ownership and usership) and spatial unit fragmentation (parcel, farm and land block or zone) (Sabates-Wheeler, 2002; Ntihinyurwa et al., 2019; Postek et al., 2019; Ntihinyurwa and de Vries, 2020).

Farmland fragmentation and dispersal are global phenomena which exhibit national and international variation. Generally, it is driven by factors ranging from inheritance traditions to historical context (e.g. land reforms under socialist governments which drove land consolidation, land grabs, or conversely, the "individualisation" of land parcels to following the disbanding of agricultural collectives) (Cungu and Swinnen, 1999; Sklenicka et al., 2014; Constantin et al., 2017). Trends in land use can also influence fragmentation via e.g. farm diversification and conservation efforts, or via rapid farm expansion which can result the ownership of multiple parcels (Bartolini and Viaggi, 2013). Land parcels may be differently sized and irregularly shaped, which can present problems for agricultural productivity (Igbozurike, 1974). Some of these factors may be intentionally adopted by farmers for the good of the farm business. For example, the inclination of farmers to expand the farm through the acquisition of more contiguous (adjacent) or noncontiguous parcel in a bid to take advantage of increased demand, whilst others can be considered as external pressure of nature and the society for example, growth in farming population given the limited land resources, and the egalitarian based land distribution through partible inheritance and culture (Binns and Binns, 1950; van Dijk, 2003; Gomes et al., 2019; Ntihinyurwa and de Vries, 2020).

Farmland fragmentation can influence agricultural production, biodiversity and ecosystem functions in diverse ways. However, such influence also depends on a number of factors, including the level of mechanisation or subsistence, the level of development of the factor market, the land tenure systems, the population density and demography of the country as well as the prevailing agricultural systems and policies (Ntihinyurwa and de Vries, 2020). For example, in countries such as the United Kingdom (UK) and other European countries where agriculture is highly mechanised and market-oriented, farmland fragmentation is generally considered detrimental and a major threat to agricultural production as it has the tendency of limiting economies of scale and centralized management of agricultural production, and consequently reduce production efficiency and sustainable land use (Davis et al., 2009; Cheng et al., 2015; de Vries, 2016; Postek et al., 2019; Ntihinyurwa and de Vries, 2020). On the other hand, in countries where agriculture remain highly subsistence in nature, farmland fragmentation may be regarded as beneficial in that it serves as an adaptive strategy to mitigate production and prices fluctuations risks and provide an opportunity for agricultural production diversification for self-sufficiency in food production and household food security (Sklenicka and Salek, 2008; Ciaian et al., 2018; Knippenberg et al., 2018; Cholo et al., 2019; Ntihinyurwa et al., 2019; 
Ntihinyurwa and de Vries, 2020). Studies by Sherlund et al. (2002) and Tan, (2005), in Cote d'Ivoire and China, respectively, have found that the increase in the number of plots has a positive relation with technical efficiency in rice production.

\subsection{Land fragmentation in Northern Ireland}

Farmland fragmentation and dispersal is pervasive in the UK and Republic of Ireland (ROI). In the UK, distances of over $32 \mathrm{~km}$ between land-parcels have been recorded (Barrington and Ilbery, 1987) and some $68 \%$ of sampled Somerset farms (Edwards, 1978), and $49 \%$ of sampled Cornish farms (Durr and Froggatt, 2002), were split across multiple land holdings. In the ROI, individual farms were associated with an average of three constituent land parcels (O'Donnell, 2013), however farms with five or more parcels have been observed (Byrne et al., 2020). As with the rest of the UK and ROI, farmland fragmentation is a "considerable feature" of Northern Ireland's (NI) agricultural landscape (EC, 2013; NIAO, 2018). Epidemiological investigations into the transmission of cattle diseases in the area allude to highly fragmented and highly interconnected farms (Abernethy et al., 2006; Campbell et al., 2020a), with ample opportunities for contact between cattle on contiguous land parcels (Denny and Wilesmith, 1999; O'Hagan et al., 2016; Campbell et al., 2020b).

From a regional perspective, livestock farming forms a significant component of NI's commercial output, and cattle farming alone comprising over $50 \%$ of the $£ 2.3$ billion agri-food sector (DAERA, 2020). Eighty-nine percent of NI's approximately 25,000 farms are associated with cattle, either via dairying, or rearing of cattle for other purposes (namely beef). The Northern Irish national cattle herd consists of some 1.6 million animals, including approximately 247,000 beef and 313,500 dairy cows, amongst others (DAERA, 2020). In NI, most production systems involve outside grazing and thus, grass availability and quality are key considerations for farmers. Traditionally, farming is a family business in NI, and farms are also relatively small (in both farm area and head of cattle) compared to those in the rest of the UK, which is considered a competitive disadvantage (McCann and Colhoun, 2007). Precisely, the average farm size in NI is 41 hectares which is significantly less than the UK average of 81 hectares (DAERA, 2017). The farms are usually operated as sole trading businesses (self-employed) or in partnerships, and very often do not involve individuals from outside of the family in the management and decision-making processes (Magee, 2002; Adenuga et al., 2018; Jack et al., 2019). Also, the majority of the farms in the region are inherited through generational succession, which creates structural difficulties in farming and contributes to farmland fragmentation (Jack et al., 2019). In addition, there is the prevalence of rental agreements based on the traditional "conacre" system, which is a short-term land rental system unique to Ireland. The system (nominally for 11 months or 364 days) permits land which can be in small patches to be let to other farmers without the need for either party to enter a long term commitment. As much as a third (about 300,000 hectares) of agricultural land in NI is farmed under the "conacre" agreements with the consequence that the land owner is not necessarily the farmer (Alexander, 1963; Olagunju et al., 2019). Besides, dairy herds are becoming increasingly larger, which may be driving demand for suitable grazing land (Adenuga et al., 2018).

Given the unique nature of farming in NI, it is believed that the different cattle management practices and production systems may be 
either a feature of, or constrained by, the highly fragmented agricultural landscape in NI. The aim of this study is to describe patterns in farmland fragmentation and farm dispersal in NI cattle farms using the Land Parcel Identification Systems (LPIS). We also quantify the extent to which farmland fragmentation differs between different cattle production systems in NI and finally, discuss how local trends in cattle farming may be impacting, or impacted by, farmland fragmentation. An understanding of the spatial arrangement of farmland across the different cattle enterprises will contribute to the development of policy framework necessary for the effective management of farms, as well as improve farm efficiency and productivity in Northern Ireland and other countries of similar farming systems. This will also assist policy makers with making informed decisions and contributes to achieving the sustainable development goals relating to land management. Previous studies on farmland fragmentation have focused mainly on the impact of farmland fragmentation on farm productivity or on forested landscape segments (Brown, 2003; LaPierre and Germain, 2005; Rahman and Rahman, 2009; Cholo et al., 2019; Ntihinyurwa et al., 2019; Ntihinyurwa and de Vries, 2020). To the best of our knowledge, there have been few studies if any that attempt to holistically analyse farmland fragmentation on a comparative basis in cattle farms in spite of the importance of the sector, and the continued fragmentation of farmlands in many European countries. As noted by Sklenicka et al. (2014), farmland fragmentation is fast becoming a limiting factor for sustainable land use in European agriculture.

The rest of the paper is organized as follows: In Section 2, we describe the methodology used in the research and provide a detailed description of the data sources including the study variables and metrics. The results are reported in Section 3 while section 4 discusses the results. Finally, we conclude in Section 5 by presenting an overview of the study outcomes and highlight the study limitations.

\section{Materials and methods}

\subsection{Study area}

The total area of NI is approx. 1,350,000 hectares (ha) (Fig. 1), with a farmed area exceeding 1,000,000 ha (one million hectares; over $75 \%$ of the region). There are approximately 25,000 farms in NI with some 20,000 enterprises (approximately 80\%) associated with cattle, including 2,600 dairy farms and 14,000 beef farms, amongst others (e.g. calf rearing, bulls etc), (DAERA, 2020). There are considerable differences between production types. Almost $40 \%$ of beef herds hold fewer than ten animals, whereas $35 \%$ of dairy farms hold $100+$ animals. Over $50 \%$ of dairy farms and $70 \%$ of beef farms reside on "Less Favoured Areas" (DAERA, 2020), defined generally as areas of poor productivity and performance. 


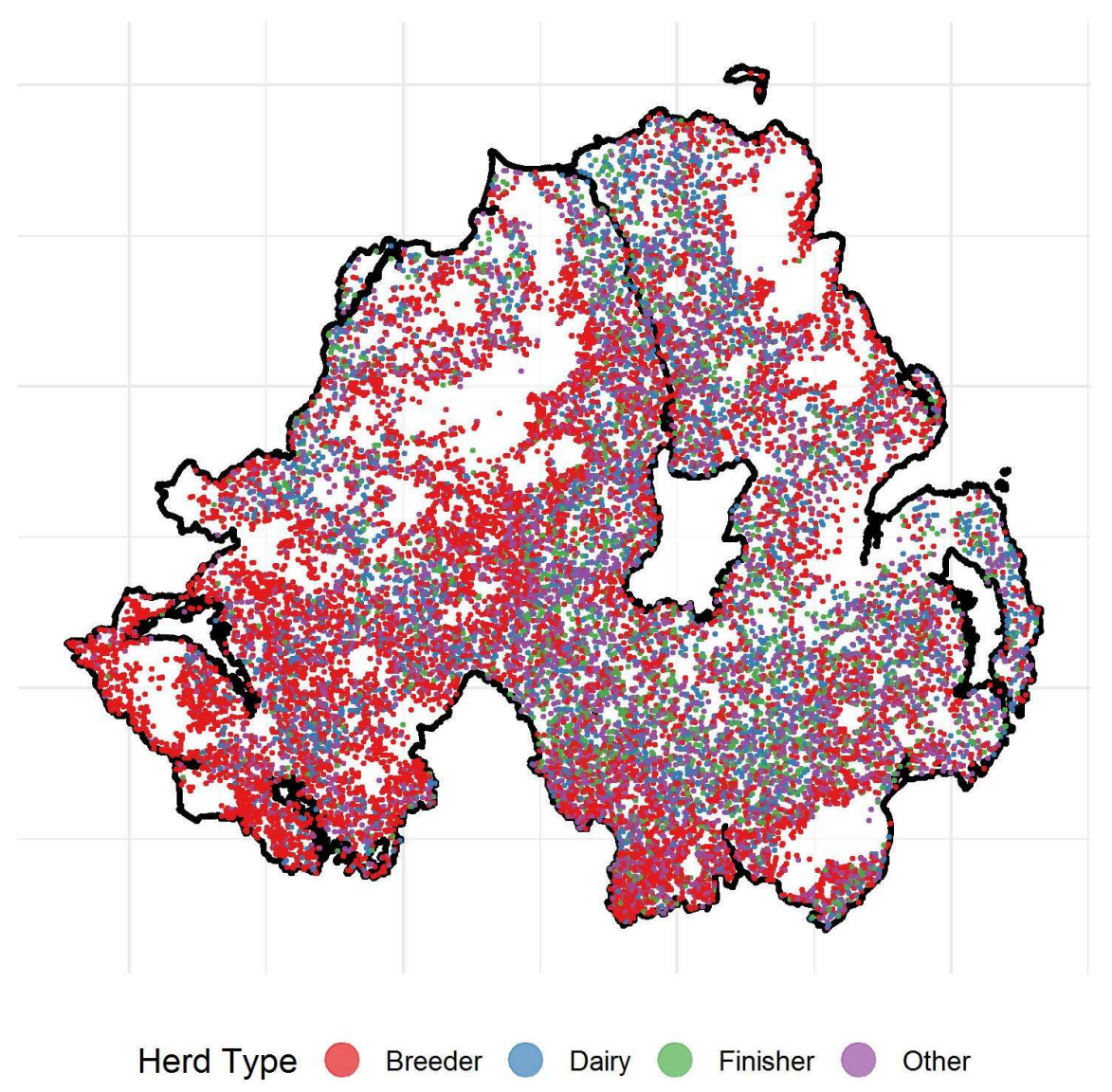

Figure 1. Distribution of cattle herds in Northern Ireland, with point locations representing the registered farmstead latitude and longitude co-ordinates.

\subsection{Data sources}

Information on the individual blocks ("land parcels") was obtained from the Northern Irish Land Parcel Identification Systems (LPIS) database. The LPIS are EU mandated geospatial databases employed in the allocation of Common Agricultural Policy (CAP) payments (Council Regulation (EC) 73/2009), however they also offer the ability to explore land use change on national scales (Bartolini and Viaggi, 2013; Zimmermann et al., 2016). The NI LPIS database is administered by the Department for Agriculture, Environment and Rural Affairs (DAERA). The data were made available in the form of shapefiles consisting of all the land parcels in NI, along with relevant metadata including the field ID, the business owner of the field, and field size in hectares (ha). These layers were provided in a per-year basis from 2015-2017. Data on cattle enterprises in NI from 2015-2017 inclusive were made available from the Animal and Public Health Information System (APHIS), also administered by DAERA (Houston, 2001). This database records information including business owner, herd identifier, herd size, herd locations, animal breeds, animal sex and animal movements, including births, deaths and between-herd purchases. Land cover data for 2015 were purchased from the Centre for Ecology and Hydrology (CEH; https://www.ceh.ac.uk/) in raster format at $25 \mathrm{~m}$ resolution (Rowland et al., 2017). Briefly, this dataset presents the dominant land cover from 21 target habitat classes per $25 \mathrm{~m}^{2}$ pixel. 


\subsection{Data processing and data cleaning}

Each land parcel polygon in the LPIS shapefile had a unique Field ID, which was mapped to a Business ID to associate individual land parcels with agricultural enterprises. Where the businesses involved cattle husbandry, the business ID was then linked with one or more Herd ID's, which enabled the spatial data to be enriched with APHIS cattle data. Some businesses were associated with multiple herds, but it was not possible to differentiate which land parcels were used by different herds. The dataset was restricted to only include Business $I D(\mathrm{~s})$ and Herd ID(s) present for all three years of the study, as transient enterprises entering or leaving cattle farming may behave differently from established businesses. The analysis was further restricted to those herds populated for all three years of the study, where populated herds had at least 1 head of cattle for each year. We hereby refer to a "farm" as the combination of unique Business ID, Herd $I D(s)$ and Field $I D(s)$ associated with a cattle business. All data were anonymised for analytical purposes.

\subsection{Defining variables and metrics}

\subsubsection{Herd classification}

Determining herd types computationally is not trivial. Cattle farmers may change their business year on year depending on market conditions, or the herd may consist of several cattle classes which makes differentiation unclear. For example, breeding dairy farms may have a large number of adult female Holsteins, but may also hold adult bulls and male calves all under the one herd identifier. Furthermore, some producers may run different production types under the one herd identifier, which introduces additional complexity when determining the main business type. We therefore opted to define a necessarily broad herd_type variable. This was based on characteristics which generally represent the main specialisations of cattle farming in NI. Dairy herds were defined as those herds with a milk licence, which also consisted of a majority of dairy breeds (e.g Holsteins, Friesians), with at least $60 \%$ of the herd consisting of female animals which are at least 12 months old. Finishing herds generally operate by purchasing in stock to fatten animals specifically for slaughter - these are usually beef cattle but increasingly includes dairy animals (Allen, 2016). We defined these herds as having a minority of the herd derived from within-herd births $(<=20 \%)$, with a majority of the herd sent directly to an abattoir $(>=51 \%)$, along with the absence of a milking licence. Breeding or suckling herds specialise in producing young animals which are usually sold onwards; these were defined by having a majority $(>=51 \%)$ of the herd derived from withinherd births, and a minority $(<=20 \%)$ of the herd sent to an abattoir, and the absence of a milking licence. This classification primarily consists of beef suckler herds. The remaining herds were classed as "Other", and includes mixed production types and rarer herd classifications such as breeding bulls. Herd size (herd_size) was defined as the median number of animals in the herd over one year, derived from monthly animal movement data.

\subsubsection{Farmland fragmentation}

We defined farmland fragmentation as the presence of single farms spread across multiple, discontinuous land parcels. Whilst an extensive variety of metrics describing farmland fragmentation and dispersal have been proposed (Igbozurike, 1974; Demetriou, 2014; Postek et al., 2019), we elected to use metrics which are clear and easy to interpret. The 
number of land parcels (i.e. "fields"; $n_{-}$fields) associated with each farm was a count of the number of land parcels associated with the business. Furthermore, a collection of individual land parcels situated together in a single functional unit was defined as a "fragment" (n_fragments). Upon visual inspection, we identified land parcels which initially appeared spatially discontinuous, but were only split by a small feature e.g. a small stream, thick hedgerow, or narrow laneway. In practice, these parcels should be considered part of the same fragment. To address this issue, a $5 \mathrm{~m}$ spatial buffer was applied when concatenating parcels into fragments (n_fragments_5m). This distance was chosen as it is the minimum width of a narrow access road in NI and therefore any distance larger than this represents a meaningful boundary between land parcels. The total farm area in hectares (total_farm_area_ha) was defined as the sum of all the land parcels associated with the farm (Supplementary Material 1, Section 2).

\subsubsection{Farm fragment dispersal}

Fragment dispersal was the extent by which land parcel fragments were spatially separated. To measure fragment dispersal, the median distance between the centroids of all fragments was calculated (median_distance_fragments_km), along with the maximum distance between the centroids of the two most distant fragments (max_distance_fragments_km). The first metric is more general representative of general fragment dispersal, whilst the second illustrates the most extreme example of fragment dispersal on the farm. As the registered farmstead is not necessarily representative of where the land parcels are located, we measured the disparity between the registered farmstead address and the associated land parcels using three different location measures. Specifically, we calculated the distance between the farmstead location from APHIS (Irish Grid reference system; latitude and longitude) and the centroid of all parcels (homestead_farmcentroid_dist_km), the centroid of the biggest land parcel (homestead_field_dist_km), and the centroid of the biggest fragment (homestead_frag_dist_km).

\subsubsection{Contact with contiguous cattle farms}

Contact with contiguous cattle farms was initially measured by counting the number of on-farm land parcels touching land parcels associated with external cattle farms. However, this metric is not particularly conservative as it could include land parcels which are not utilised for cattle farming. Indeed, some cattle farmers in NI also farm sheep, which are usually grazed on expansive upland land parcels unsuitable for cattle. To overcome this bias, we subset the data to only include land parcels suitable for cattle grazing, with $>=80 \%$ area of Land Cover Map (LCM) classification 4 (improved grassland) or LCM classification 5 (neutral grassland). We were then able to derive the number of contiguous land parcels where both internal and external parcels were suitable for cattle grazing (n_touching_cattle_fields_grazing). The total shared perimeter boundary between the contiguous cattle farms was also calculated, and similarly refined to only include boundaries where both internal and external land parcels were classified as LCM4 or LCM5 (total_shared_boundary_grazing_km).

\subsubsection{Land classification}

The predominant Land Cover Map (LCM) classifications present on cattle farms were determined by extracting the area associated with each 
of the twenty-one LCM categories on a per-farm basis). The percentage of land classified as LCM 4 and LCM 5 (LCM4_5) was then calculated.

\subsection{Data visualisation and statistical analysis}

\subsubsection{Region wide variation in land parcellisation and area}

Large-scale spatial variation in the number land-parcels associated with cattle enterprises, and the mean land parcel size was visualised on a net of 152 regular hexagonal grid cells, with hexagon centroids $10 \mathrm{~km}$ apart. Assessments for changes in these outcomes across Euclidian space (via the explanatory continuous variables hexagon_centroid_lat and hexagon_centroid_long), and through time (via the categorical year_of_study variable), were carried out using Gaussian Generalised Linear Models (GLMs). The model coefficient (Coef.) and the 95\% lower and upper confidence intervals $(95 \% \mathrm{CI})$ were reported.

\subsubsection{Farm-level variation}

Farm-level metrics of farm fragmentation, farm dispersal, contact with neighbouring farms, and LCM classifications, are presented as summary data with measures of precision (median and Inter-Quartile Range; IQR). We also tested for associations between production type and farm fragmentation, fragment dispersal, contact with neighbouring farms, farm area and LCM classifications using linear-by-linear chisquare test for ordered categorical variables (Agresti, 2007), and GLMs for continuous outcomes. We elected to fit such models using the Gaussian distribution, as these are the most easily interpretable.

All data were managed in MS SQL 2016 and analysed using R version 3.3.4 (R Core Team, 2013). All GIS processing was carried out in the $R$ statistical programming environment, using the packages raster (Hijmans and Etten, 2012), rgdal (Bivand et al., 2010) and regeos (Bivand and Rundel, 2017). Figures were constructed by the authors using ggplot2 (Wickham, 2009), and Chi-Squared tests were carried out using coin (Hothorn et al., 2006). Due to GDPR concerns, we are unable to make the underlying research data available, however we have included the code and results generated in this analysis as a Supplementary Material $R$ Markdown file (Supplementary Material 1).

\section{Results}

\subsection{Descriptive statistics}

The total number of land parcels in NI between 2015 and 2017 was $736,866(\mathrm{SD}=355)$. Approximately $70 \%$ of these were associated with cattle enterprises (mean per-year $=516,798$; $\mathrm{SD}=1,352$ ). The dataset initially contained 24,495 Business IDs and 26,741 Herd IDs. After the removal of businesses and herds which were not present or populated for the whole of the study period, the final number of Business IDs was $17,744(72 \%)$, and the final number of Herd IDs was $19,008(71 \%)$. As relevant metrics were generated for each of the 19,008 herds for the three years 2015-2017, there were 57,024 total observations. Between year variation was negligible at the farm level for the contact metrics (Supplementary Material, Section 2), and we therefore report most data aggregated across the three years of the study.

\subsection{Region wide variation in land parcellisation and area}

Fig. 2A-B illustrates the region-wide differences in land parcellisation and land parcel area. Per $10 \mathrm{~km}$ cell, there were 3,304 land parcels associated with cattle farms (IQR: 2,317-4,033). Although there 
was a general increase in the total number of land parcels recruited into cattle farming through the study period (2015, n parcels $=516,060 ; 2017$, $\mathrm{n}$ parcels $=518,359)$, there was no evidence of significant variation between years (GLM, compared to null model using ANOVA, F = 0.01, df $=2, p=0.99)$. A negative relationship was detected between the number of land parcels per-cell and latitude (south to north) with 16 fewer land parcels on average for every $1 \mathrm{~km}$ increase in latitude (GLM Coef. $=-16.04$, 95\%CI: $-19.20,-12.88)$. There was some evidence that the number of land parcels decreased with longitude, with three fewer land parcels per $1 \mathrm{~km}$ increase east to west (GLM Coef. $=-3.24,95 \% \mathrm{CI}:-0.45,-6.01)$. The median parcel area was 1.5ha (IQR: 1.3ha-1.9ha), which was consistent throughout all three years of the study (GLM, compared to null model using ANOVA, $\mathrm{F}=0.13, \mathrm{df}=2, \mathrm{p}=0.88$ ). Land parcel size was observed to increase marginally by 0.009 ha per $1 \mathrm{~km}$ increase in latitude (GLM Coef. $=0.009,95 \% \mathrm{CI}: 0.007,0.01)$, but there was no observable relationship with longitude (GLM Coef. $=0.0007,95 \%$ CI: $-0.005,0.002$ ). 
A

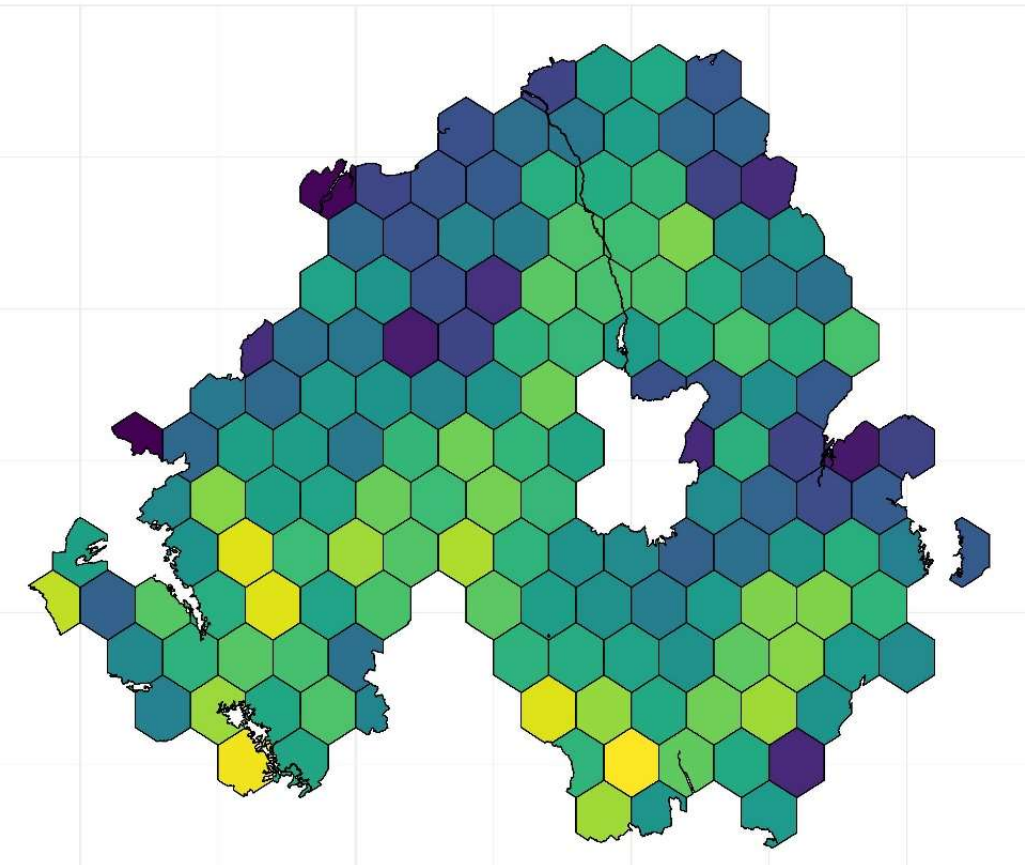

B

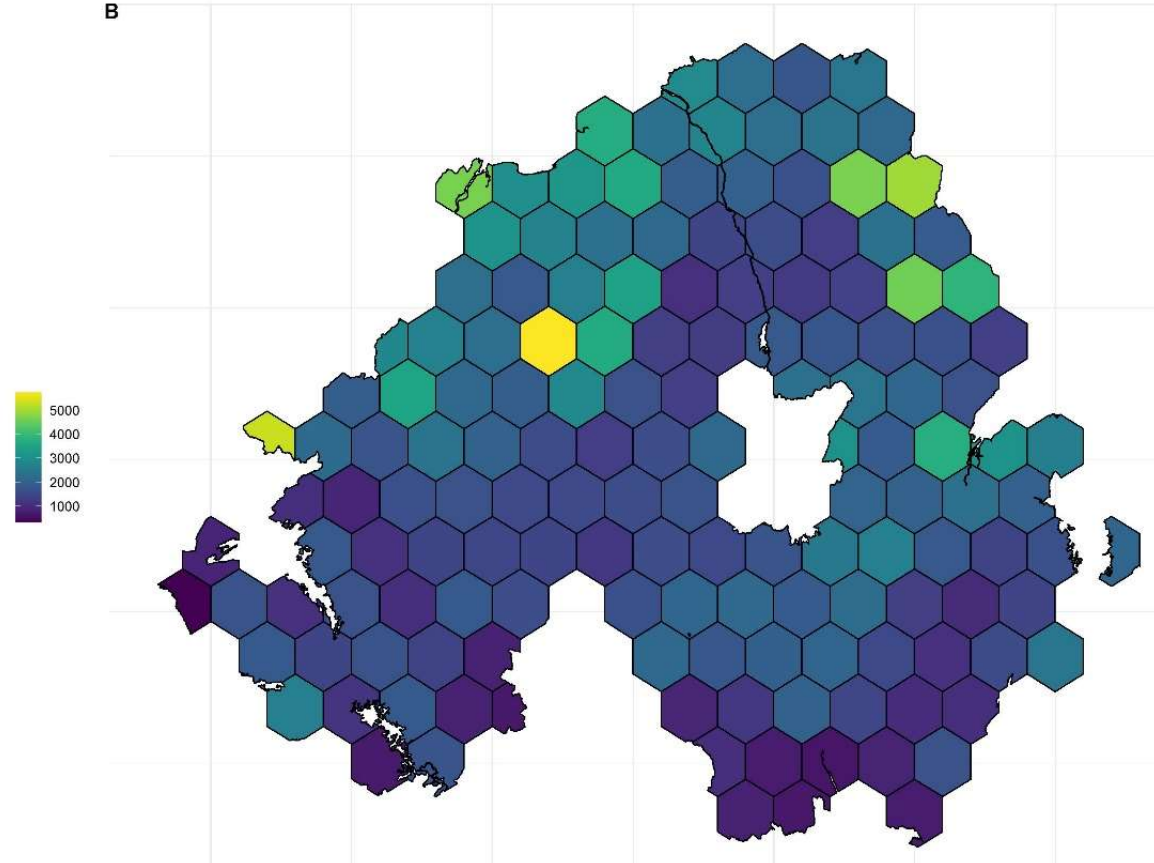

Figure 2A-B: Hexagon plots showing (A) the number of land parcels associated with cattle farming per 10km hexagon cell, and (B) the mean area of land parcels associated with cattle farming per $10 \mathrm{~km}$ hexagon cell. 


\subsection{Farm-level variation in farm fragmentation}

\subsubsection{Herd characteristics}

In $2015,49.8 \%$ of herds were classed as breeding $(\mathrm{n}=9,464), 14.4 \%$ ( $\mathrm{n}$ $=2,740)$ were dairy, $10.4 \%$ were finishers $(n=1,970)$ and $25.4 \%$ were classed as "other" $(\mathrm{n}=4,834)$; this remained broadly consistent in all years of the study (Supplementary Material, Section 1). The vast majority of businesses $(93.3 \%)$ were associated with a single cattle herd. Herd size varied with production type; dairy herds were the largest, with a median of 171 animals (IQR: 96-277), finisher herds had 46 animals (IQR: 21-97) and breeding herds had 30 cattle (IQR: 17-54). Herds classed as "other" held 38 animals on average (IQR: 15-84).

\subsubsection{Farm land fragmentation}

The median number of land parcels per-farm was 24 (IQR: 14-39; $\max =444$ ), however the median number of fragments was 6 (IQR 4-10; $\max =81$ ), which dropped to 3 fragments after the application of the $5 \mathrm{~m}$ buffer (IQR: 2-6; max = 47). In 2015, over $16 \%$ of cattle farms $(n=3,134)$ consisted of a single fragment, whilst $35 \%$ of farms $(n=6,755)$ were comprised of five or more fragments; this did not vary notably during the three years of the study (Table 1). To investigate whether farm fragmentation varied by farm area, farms were categorised by size on the basis of percentiles. Farms with total areas $<16.4$ ha $\left(25^{\text {th }}\right.$ percentile) were classed as "small", farms $>=16.4$ ha $<=59.1$ ha $\left(75^{\text {th }}\right.$ percentile) were classed as "medium" and farms larger than 59.1ha were classed as "large". An ordinal relationship between farm fragmentation and farm area was detected (Linear-by-Linear Association Test, $Z=118.73 .1, p<0.001$ ), with larger farms exhibiting greater fragmentation, Fig. 3A. Out of all the nonfragmented farms, some 53\% ( $\mathrm{n}=4,995)$ were classified as small, compared to $0.1 \%(n=17)$ of farms classed as very highly fragmented. Conversely, $4.3 \%(\mathrm{n}=405)$ of non-fragmented farms were classified as large, compared to $81 \%(\mathrm{n}=2,710)$ of very highly fragmented farms (Supplementary Material, Section 3.1.1, Table 3) 


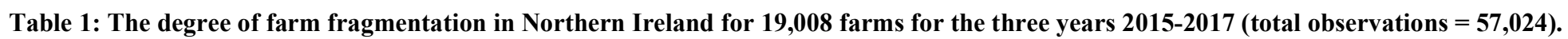

\begin{tabular}{lccccc}
\hline Number of fragments per farm & Description & $\mathbf{2 0 1 5}$ & $\mathbf{2 0 1 6}$ & $\mathbf{2 0 1 7}$ & All years \\
\hline 1 & No fragmentation & $3,134(16.5 \%)$ & $3,178(16.7 \%)$ & $3,164(16.7 \%)$ & $9,476(16.6 \%)$ \\
$2-4$ & Little fragmentation & $9,119(48.0 \%)$ & $9,041(47.6 \%)$ & $9,004(47.4 \%)$ & $27,164(47.6 \%)$ \\
$5-7$ & Medium fragmentation & $4,137(21.8 \%)$ & $4,114(21.6 \%)$ & $4,102(21.6 \%)$ & $12,353(21.7 \%)$ \\
$8-10$ & High fragmentation & $1,546(8.1 \%)$ & $1,574(8.3 \%)$ & $1,571(8.3 \%)$ & $4,691(8.2 \%)$ \\
$11+$ & Very high fragmentation & $1,072(5.6 \%)$ & $1,101(5.8 \%)$ & $1,167(6.1 \%)$ & $3,340(5.9 \%)$ \\
Total & & 1,9008 & 1,9008 & 1,9008 & 57,024 \\
\hline
\end{tabular}




\subsubsection{Fragment dispersal}

The median distance between fragments was $1.38 \mathrm{~km}$ (IQR: $0.52 \mathrm{~km}-$ $3.05 \mathrm{~km}, \max =120.0 \mathrm{~km}$ ), and was categorised using percentiles, following the approach taken to categorise farm area. Farms with fragments less than $0.52 \mathrm{~km}$ apart on average ( $25^{\text {th }}$ percentile) were classed as "low dispersal"; farms with fragments $>=0.52 \mathrm{~km}$ and $<3.05 \mathrm{~km}$ apart were classed as "medium dispersal", and farms with fragments $>3.05 \mathrm{~km}$ apart ( $75^{\text {th }}$ percentile) were classed as "high dispersal". Farm dispersal was positively associated with farm fragmentation (Linear-by-Linear Association Test, $\mathrm{Z}=121.69$, $\mathrm{p}<0.001$ ), (Fig. 3B). The maximum distance between fragments differed only marginally to the median distance between fragments, at $2.32 \mathrm{~km}$ (IQR: $0.64 \mathrm{~km}-6.09 \mathrm{~km}$, $\max =152.0 \mathrm{~km}$ ), with a strong, significant positive correlation between both variables $(\mathrm{r}=$ $0.93)$. Whilst $100 \%(n=9,476)$ of non-fragmented farms exhibited low dispersal (i.e. no dispersal in this instance), $50 \%(n=1,683)$ of very highly fragmented farms where characterised by highly dispersed fragments (Supplementary Material Section 3.1.2, Table 5).

The median distance between the registered homestead and the farm centroid (i.e. all parcels) was $0.67 \mathrm{~km}$ (IQR: $0.27 \mathrm{~km}-1.71 \mathrm{~km}$, max $=$ $112.8 \mathrm{~km})$. Similar values were obtained for the distance between the homestead and largest land parcel only; $0.69 \mathrm{~km}$ (IQR: $0.31 \mathrm{~km}-2.07 \mathrm{~km}$, $\max =127.5 \mathrm{~km})$, whilst the distance between the farmstead and the largest fragment was $0.47 \mathrm{~km}$ (IQR: $0.22 \mathrm{~km}-1.58 \mathrm{~km}$, $\max =127.5 \mathrm{~km}$ ).

\subsubsection{Contact with contiguous farms}

The average cattle farm was in contact with 47 land parcels (IQR: 2876) associated with other cattle farms. Restricting this to only include both internal and external land parcels suitable for cattle grazing (i.e. LCM 4 and 5) resulted in contiguous contact between 13 land parcels (IQR: $7-21$ ), equivalent to a shared perimeter of $2.84 \mathrm{~km}$ (IQR: $1.48 \mathrm{~km}-$ $4.94 \mathrm{~km})$. After categorising this variable using percentiles as "contact level" (low contact $<1.48 \mathrm{~km}$, medium contact $>=1.48 \mathrm{~km}<=4.94 \mathrm{~km}$, high contact $>4.94 \mathrm{~km}$ ), a positive relationship between farm fragmentation and contact category was identified (Linear-by-Linear Association Test, $\mathrm{Z}=125.63, \mathrm{p}<0.001)$, Fig. 3C. Some $55 \%$ of non-fragmented farms $(\mathrm{n}=$ $5,194)$ were classified as low contact with external farms, with only $1.8 \%$ classed as high contact $(n=170)$. The opposite was observed for very highly fragmented farms, however, with $1.9 \%(n=62)$ classed low contact and $82 \%(\mathrm{n}=2,741)$ classed as high contact (Supplementary Material, Section 3.1.3, Table 7)

\subsubsection{Land Classification}

On the average cattle farm, $84.3 \%$ of land (IQR: $65.2 \%-94.4 \%$ ) was classified as LCM4; when LCM5 land was included, this increased to 87.7\% (IQR: 70.0\%-96.1\%). The percentage of land LCM4 and LCM5 perfarm was found to decrease marginally for every $1 \mathrm{~km}$ increase in latitude from south to north (GLM Coef. $=-9.8 \times 10^{-5}, 95 \%$ CI: $-1.08 \times 10^{-4},-8.75 \times 10^{-}$ $\left.{ }^{5}\right)$, Fig. 4. 
A

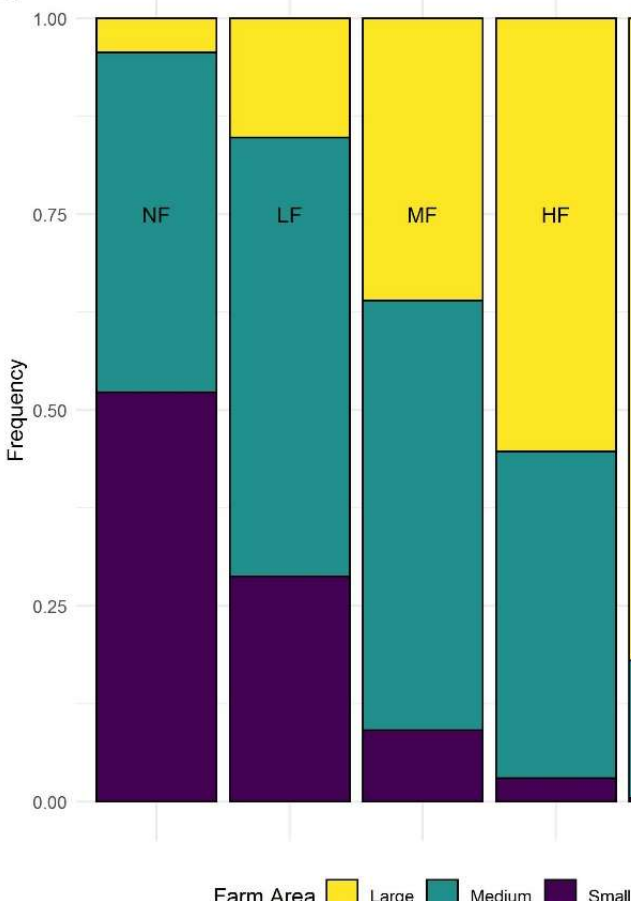

B

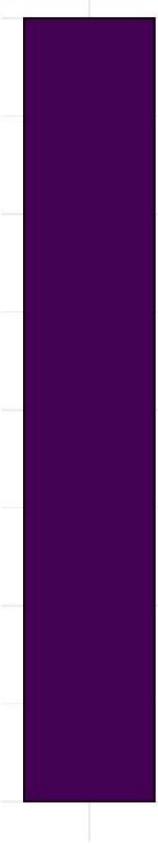

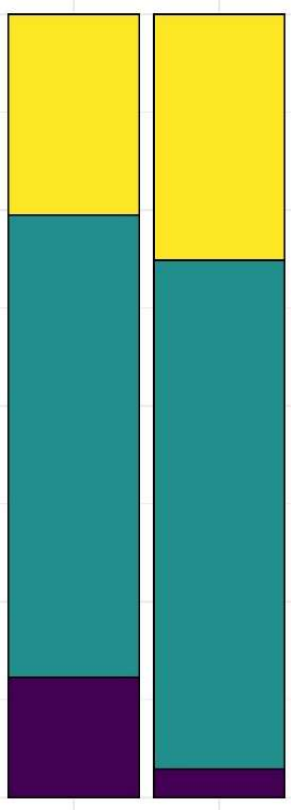
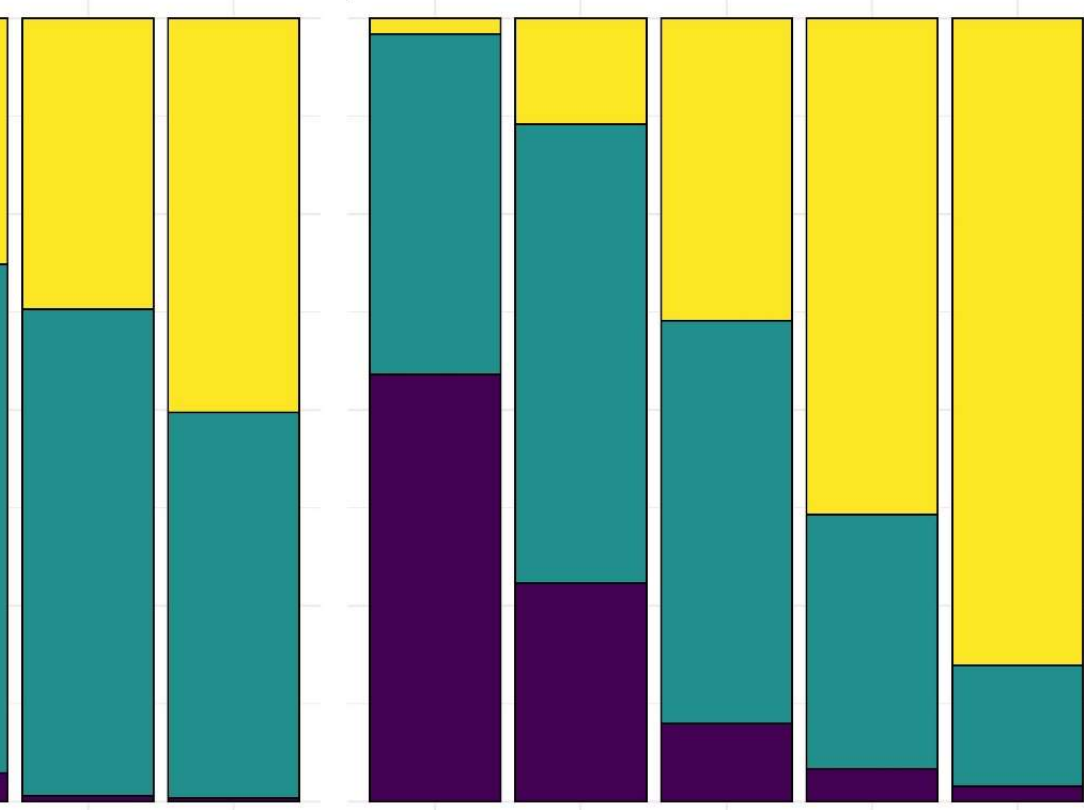

Fragment Dispersal $\square$ High $\square$ Medium $\square$ Low

Contact Category $\square$ High $\square$ Medium

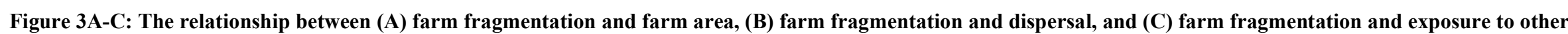

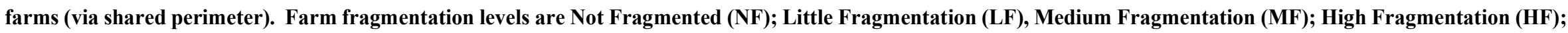
Very High Fragmentation (VF) 


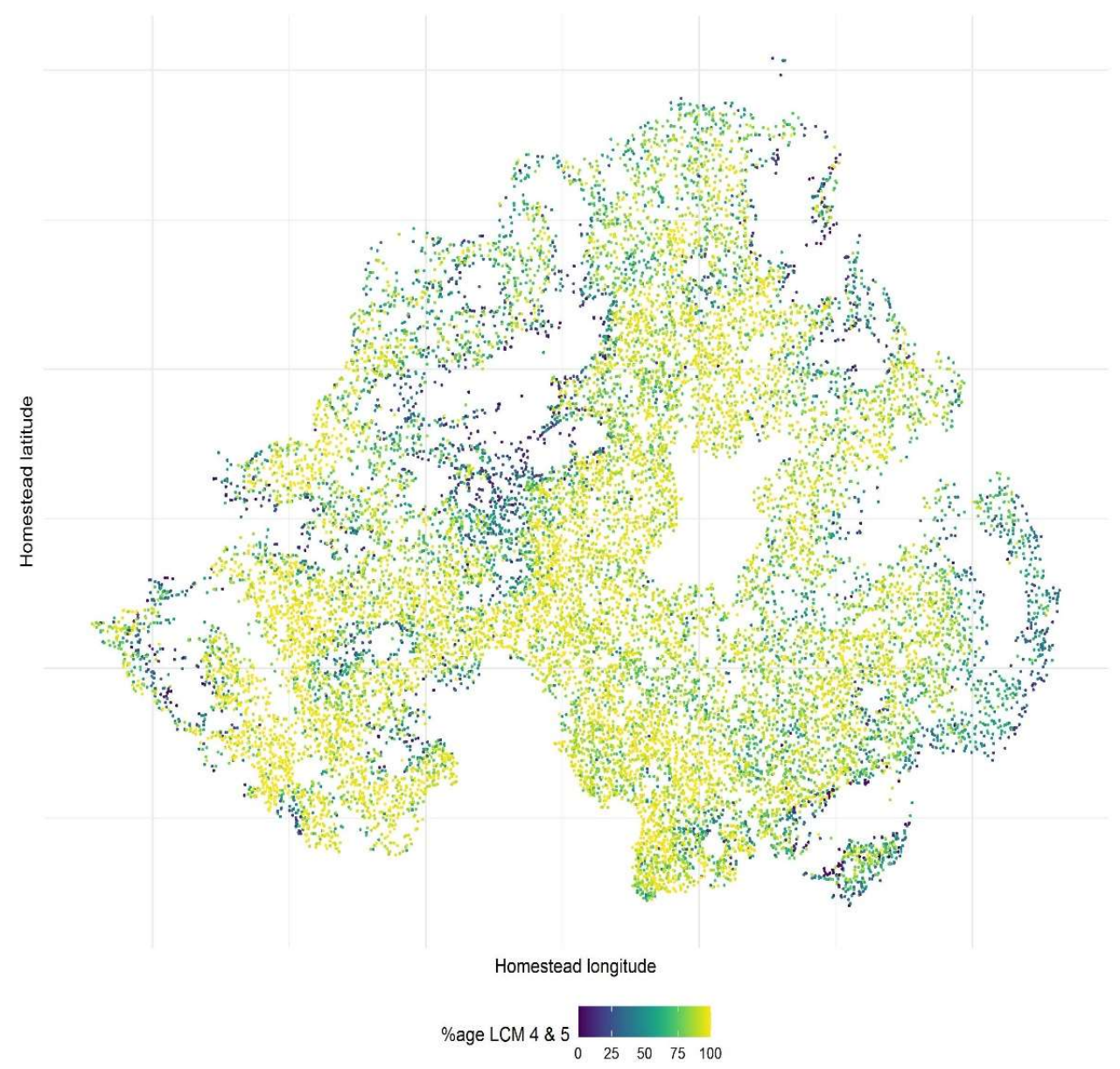

Figure 4. The percentage of land classified as Land Cover Model (LCM) 4 and 5, on a per-farm basis. The farm location is mapped using the latitude and longitude of the registered homestead.

\subsection{The variation of farm fragmentation, farm dispersal and farm contact with} production type

At 65ha (IQR: 42ha-100ha), dairy farms occupied almost twice the area of finisher farms (32ha; IQR: 17ha-58ha) and almost three times the area of breeder farms (26ha, IQR: 15ha-46ha). Dairy farms also had almost twice as many land parcels (39; IQR: 27-56) as any of the other herd types (Table 2) and indeed, some $11.4 \%$ of dairy farms were very highly fragmented, compared to $5.7 \%$ of finisher farms and $3.8 \%$ of breeder farms (Fig, 5A, Supplementary Material Section 3.2.1, Table 8). There was no evidence that the number of fragments varied at the farm level varied through the three years of the study (GLM, compared to null model using ANOVA, $\mathrm{F}=2.10, \mathrm{df}=2, \mathrm{p}=0.12$; Supplementary Material, Section 2.2.1). When the analysis was restricted to dairy herds, however, a marginal increase was observed in the number of land parcels per farm $(2015$, median number of parcels $=39 ; 2017$, median number of parcels $=$ 40, Supplementary Material, Section 3.2.2). No other clear trends regarding the number of land parcels and herd-types were observed. The land fragments in dairy farms were more dispersed than in other production types on average, however the maximal distances between fragments was seen in finisher herds, where distances of $152 \mathrm{~km}$ between fragments were recorded (Table 2, Supplementary Material, Section 3.2). 
When comparing the distance between the homestead and the largest fragment, dairy farms were slightly closer than other herd types, although the real differences in the distances involved were small (Table 2, Fig 5B). There were twice as many fields, and twice as much perimeter in contact with contiguous farms in dairy herds than for other production types (Table 2, Fig 5C). There was also a relationship between production type and LCM coverage, with dairy farms consisting of slightly higher percentages of LCM classification 4 and 5, than other herd types (Table 2). 
A

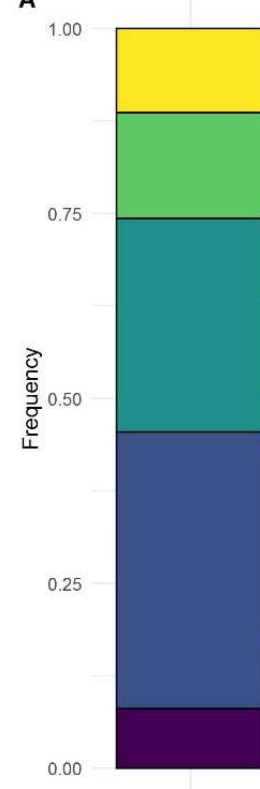

Dairy

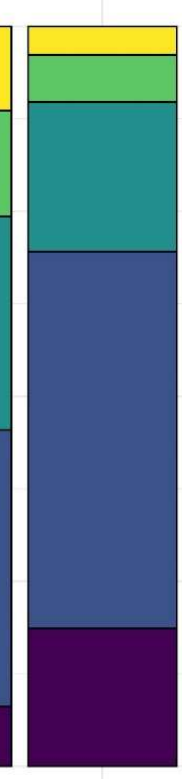

Breeder Herd Type
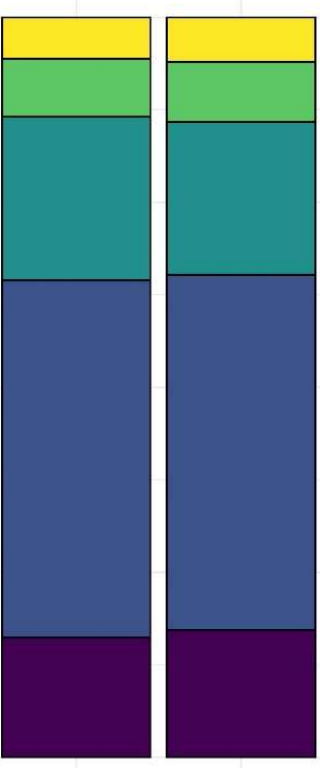

Other

Farm Fragmentation $\square$ VF $\square$ HF $\square$ MF

B

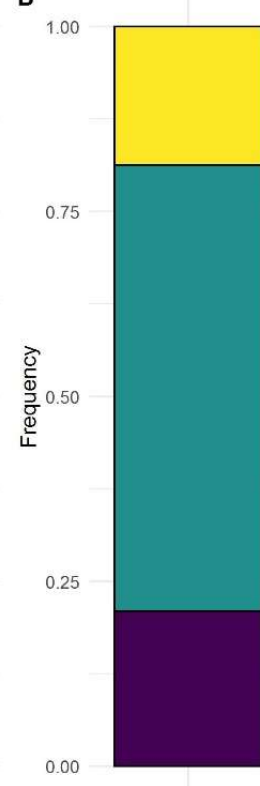

Dairy

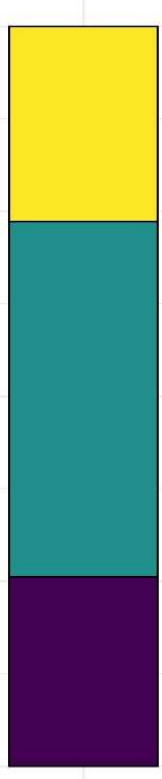

Breeder

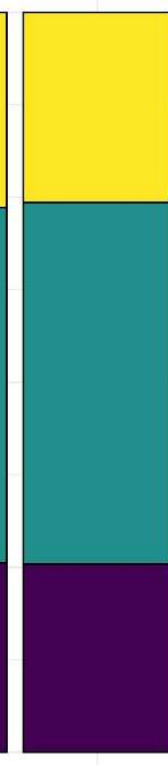

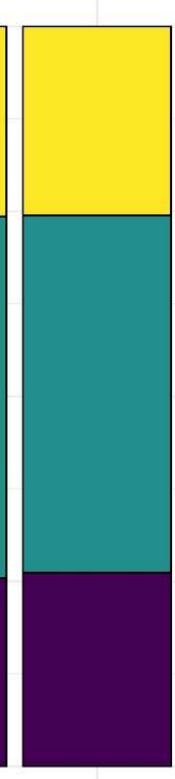

Other

Homestead-Fragment Distance

C

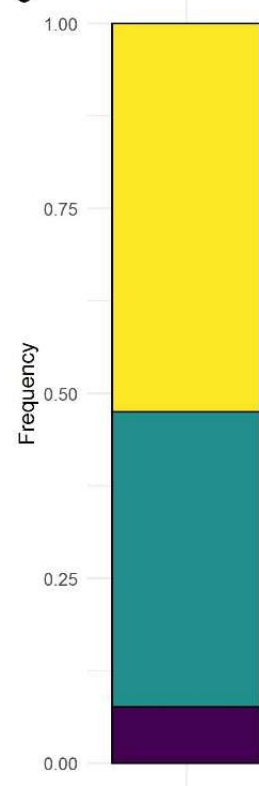

Dairy

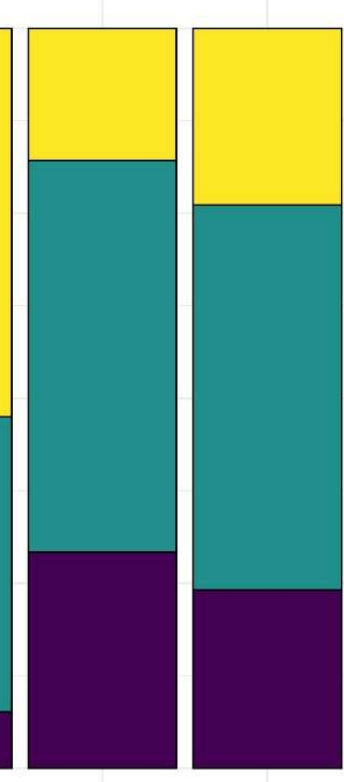

Breeder Finis Contact Category $\square$ High $\square$ Medium

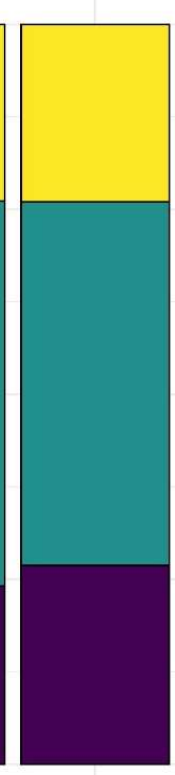

Other

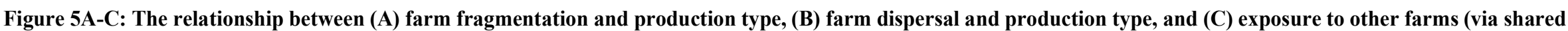

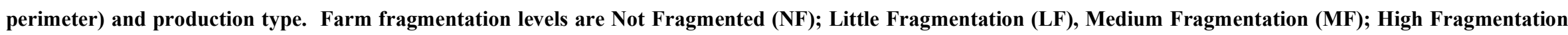
(HF); Very High Fragmentation (VF) 
Table 2: Measures of farm fragmentation, farm dispersal, farm contact and land classification associated with different production types. The test statistics refer to Kruskal-Wallis Chi-squared tests.

\begin{tabular}{|c|c|c|c|c|c|c|c|c|}
\hline Variable & Herd Type & Min & Q1 & Med & Q3 & Max & $\mathrm{X}^{2}$ & (p) \\
\hline \multirow{4}{*}{ total_farm_area_ha } & Breeder & 0.00 & 15.00 & 26.00 & 46.00 & 1418 & \multirow{4}{*}{6621} & \multirow{4}{*}{$\mathrm{p}<0.001$} \\
\hline & Dairy & 2.00 & 42.00 & 65.00 & 100.00 & 1973 & & \\
\hline & Finisher & 2.00 & 17.00 & 32.00 & 58.00 & 1007 & & \\
\hline & Other & 0.00 & 14.00 & 28.00 & 57.00 & 3252 & & \\
\hline \multirow{4}{*}{ n_fields } & Breeder & 0.00 & 13.00 & 22.00 & 35.00 & 423.00 & \multirow{4}{*}{4537} & \multirow{4}{*}{$\mathrm{p}<0.001$} \\
\hline & Dairy & 2.00 & 27.00 & 39.00 & 56.00 & 379.00 & & \\
\hline & Finisher & 1.00 & 13.00 & 21.00 & 35.00 & 219.00 & & \\
\hline & Other & 0.00 & 12.00 & 22.00 & 37.00 & 444.00 & & \\
\hline \multirow{4}{*}{$\mathrm{n}$ _fragments_5m } & Breeder & 0.00 & 2.00 & 3.00 & 5.00 & 35.00 & \multirow{4}{*}{2117} & \multirow{4}{*}{$\mathrm{p}<0.001$} \\
\hline & Dairy & 1.00 & 3.00 & 5.00 & 8.00 & 33.00 & & \\
\hline & Finisher & 1.00 & 2.00 & 3.00 & 6.00 & 32.00 & & \\
\hline & Other & 0.00 & 2.00 & 3.00 & 6.00 & 47.00 & & \\
\hline \multirow{3}{*}{ median_distance_fragments_km } & Breeder & 0.00 & 0.43 & 1.21 & 2.95 & 120.00 & \multirow{3}{*}{670} & \multirow{3}{*}{$\mathrm{p}<0.001$} \\
\hline & Dairy & 0.00 & 1.04 & 1.88 & 3.21 & 97.09 & & \\
\hline & Finisher & 0.00 & 0.50 & 1.34 & 3.04 & 82.97 & & \\
\hline
\end{tabular}




\begin{tabular}{|c|c|c|c|c|c|c|c|c|}
\hline & Other & 0.00 & 0.47 & 1.36 & 3.05 & 105.15 & & \\
\hline \multirow{4}{*}{ max_distance_fragments_km } & Breeder & 0.00 & 0.50 & 2.00 & 5.50 & 129.10 & \multirow{4}{*}{1129} & \multirow{4}{*}{$\mathrm{p}<0.001$} \\
\hline & Dairy & 0.00 & 1.70 & 3.80 & 7.40 & 117.2 & & \\
\hline & Finisher & 0.00 & 0.60 & 2.20 & 6.00 & 152.00 & & \\
\hline & Other & 0.00 & 0.60 & 2.20 & 6.10 & 117.50 & & \\
\hline \multirow{4}{*}{ homestead_fragment_distance_km } & Breeder & 0.01 & 0.22 & 0.49 & 1.71 & 120.83 & \multirow{5}{*}{14.96} & \multirow{5}{*}{$p=0.002$} \\
\hline & Dairy & 0.01 & 0.25 & 0.44 & 1.11 & 114.34 & & \\
\hline & Finisher & 0.00 & 0.22 & 0.44 & 1.70 & 127.54 & & \\
\hline & Other & 0.00 & 0.22 & 0.47 & 1.64 & 109.33 & & \\
\hline \multirow{4}{*}{ total_shared_boundary_grazing_km } & Breeder & 0.00 & 1.29 & 2.46 & 4.13 & 33.30 & & \\
\hline & Dairy & 0.00 & 3.12 & 5.14 & 7.81 & 44.10 & \multirow{3}{*}{4702} & \multirow{3}{*}{$\mathrm{p}<0.001$} \\
\hline & Finisher & 0.00 & 1.53 & 2.85 & 4.84 & 33.52 & & \\
\hline & Other & 0.00 & 1.39 & 2.69 & 4.85 & 28.57 & & \\
\hline \multirow{4}{*}{ percent_LCM4_5 } & Breeder & 0.00 & 63.00 & 86.00 & 96.00 & 100.00 & \multirow{4}{*}{493} & \multirow{4}{*}{$\mathrm{p}<0.001$} \\
\hline & Dairy & 1.00 & 79.00 & 90.00 & 96.00 & 100.00 & & \\
\hline & Finisher & 1.00 & 76.40 & 89.00 & 96.00 & 100.00 & & \\
\hline & Other & 0.00 & 72.90 & 89.00 & 96.00 & 100.00 & & \\
\hline
\end{tabular}




\section{Discussion}

Farm fragmentation is considered to be a defining feature of the Northern Irish farming landscape, potentially impacting aspects of agriculture ranging from production output, to the transmission of livestock diseases. Until now, however, our understanding of the degree of fragmentation was largely limited to a few highly localised epidemiological studies and reports (Denny and Wilesmith, 1999; Abernethy et al., 2006; O'Hagan et al., 2016; Campbell et al., 2020a). Our results confirm the presence of highly parcelled land, with over 5,000 individual land-parcels per $10 \mathrm{~km}$ hexagon cell in some areas. We observe a general trend of increased parcellisation in the south of NI compared to the north, concurrent with increasingly smaller land parcels. This is also reflected in the greater number of cattle farms in the south of NI compared to the north of the region (DAERA, 2020). We posit that land quality is driving this pattern. Thus, the land in the south of NI is understood to offer better grazing land than in the north of NI, due to the availability of lowland grazing (however, some very poor "Less Favoured Areas" are still present (DAERA, 2020)). The better grazing quality likely results in smaller parcels, as less land is required to meet grazing requirements. Given that the south of NI is less suitable for grazing and conversely, more suited to arable production, the reduced parcellisation in the north of NI could also potentially reflect a historical legacy of hedgerow removal to facilitate efficient crop production.

Whilst levels of farm fragmentation in NI were generally high $(35 \%$ of cattle farms consist of 5 or more fragments), there was considerable variation with production type. Higher levels of fragmentation and dispersal were observed in dairy production than breeding herds, finisher herds and any other herd types. We posit that the presence of highly fragmented dairy farms may be associated with a rapid expansion of the dairy sector which might be linked to the abolition of the milk quota system in 2015, to allow dairy farmers in the EU to produce as much milk as they can after 31 years of quota restriction (Adenuga et al., 2020). Although, quota was not binding in Northern Ireland towards the end of the quota years, study by Adenuga et al. (2020) has shown that the abolition of the milk quota system has varying effects on different farm types such that the larger farm types have greater tendency to expand compared to the smaller farm types. This may provide an explanation for our results, where we found that larger farms tended to be more fragmented than smaller farms. Specifically for dairy farms, the drive to take advantage of the milk quota abolition may have resulted in the greater fragmentation of land, whereby the largest fragment is possibly the original land near the premises and as the farm has expanded, assimilated more distal parcels as they become available, despite their distance from the original holding. Our results are in line with those previous studies where it was found that the level and type of farmland fragmentation can be influenced by the type of enterprise and the level of market activity in the sector (van Dijk, 2003; Asiama et al., 2017). Indeed, our data allude to this trend, with marginal increases in the number of fragments associated with dairy farms from 2015 and 2017. However, the source of these new land parcels remains to be seen; dairy farms may be assimilating land associated with other cattle production types and consuming parcels from farmers which have exited production, or else recruiting new parcels into dairy production from outside of the cattle 
industry. This study, however, did not specifically investigate the origin and fate of individual parcels, and given that there was no statistical evidence for any particular trend in these observations, any conclusions regarding land use change would be speculative. Another possible factor contributing to the increase of farmland fragmentation may be attributed to the conacre land rental system unique to the island of Ireland, which allows farm businesses to rent grazing land without entering into a longterm agreements.

An alternative explanation for the high levels of fragmentation in dairy farms lies in how the herd is distributed across land parcels. Many dairy herds consist of different groups of animals, not just milking cows, including calves, heifers, or bulls. A localised study in the South East of NI found that milking dairy cows were only grazed on land parcels connected to the main premises throughout the grazing season, however, dairy calves, heifers, and bullocks were grazed on the fragmented land parcels, possibly because those life stages would not require as many interventions as milking cows (Campbell et al. 2020a). Indeed, our present study found that despite overall higher levels of fragment dispersal in dairy farms, the distance between the homestead and the largest fragment was smaller for dairy herds than all herd types, suggesting a nucleus of land parcels in the proximity of the main premises. The Campbell et al. (2020a) study also identified a statistically significant difference in the amount of time beef and dairy herds spent grazing on fragmented land parcels away from the homestead (47\% and $41 \%$ respectively). Thus, whilst dairy farms themselves are more fragmented than beef farms, the main milking herd may not necessarily be routinely grazed on fragmented land. Further evaluation is needed, as the Campbell et al. (2020) study only included 18 farms and was set within a limited geographical area.

These findings on farm fragmentation, fragment dispersal and contact with other farms have critical implications for cattle epidemiology. Livestock residing on fragmented land may be exposed to diseases from neighbouring infection sources, including contiguous infected livestock and diseased wildlife. In the UK (including NI) and ROI, farmland fragmentation is hypothesised to contribute to the maintenance and spread of economically important livestock diseases such as bovine tuberculosis (bTB) (Denny and Wilesmith, 1999), Bovine Diarrhoea Virus (BVD) (Barrett et al., 2011), and brucellosis (Abernethy et al., 2011; Allen et al., 2015), amongst others. Our findings confirm the highly connected nature of pastures in NI, which could potentially expose cattle to many contiguous herds. It may be more useful in the future to consider a contact "pasture network" for modelling disease spread in Northern Irish cattle herds (Palisson et al., 2017), as opposed to a movement network only (Brown et al., 2019). Furthermore, spatial epidemiological studies may be criticised as the registered farmstead address may differ considerably from the location of the herd, and/or geospatial data may be imprecise (Durr and Froggatt, 2002). Our results show that despite relatively high levels of fragmentation, the median distance between the individual fragments was found to be less than $3.05 \mathrm{~km}$ in $75 \%$ of farms. This suggests that on the whole, the majority of individual fragments are in relatively close proximity to each other and the registered farmstead address. We would suggest, therefore, that at broad spatial scales (eg (Milne et al., 2020), the error introduced by imprecise herd locations may be minimal. For studies taking place at 
much smaller spatial extents, however, the discrepancies introduced from spatial irregularities may be of greater consequence.

From a production efficiency perspective, the high rate of farmland fragmentation may result in diseconomies of scale. Highly fragmented land may also prohibit increases in herd size; it is already noted that herd sizes in NI are generally smaller than those in GB, and larger producers may have more bargaining power than smaller ones. Thus, in 2012, only $13 \%$ of slaughtered finishing cattle in NI originated in herds with up to 20 animals. In GB, the equivalent figure was just 5\% (Economics, 2013). Farmlands in NI are already small in size compared to farms in other regions of the UK, and further reduction in parcels resulting from extreme farmland fragmentation may make the land less accessible for mechanization, which could consequently have a limiting effect on agricultural productivity and sustainable farm management. Specifically, farmland fragmentation could reduce both labour and land productivity through change in the marginal output of agricultural inputs, as well as increase agricultural production cost for example, through additional transport cost in moving between parcels, time taken to move cattle between parcels, and increasing logistical complexities of herd management across multiple fragments of land (e.g. rounding up animals for routine disease testing). These can all directly affect agricultural production and farm profitability.

The fragmentation of farmland can also have some consequence on the social fabric of the rural landscape and the environment especially in relation to loss of biodiversity (Sklenicka et al., 2014; Cheng et al., 2015). Already, sixty-nine percent of the total agricultural area farmed in the region is categorised as "less favoured", compared to 51 percent for the rest of the UK and 61 percent for the EU15 (DAERA, 2019). Further farmland fragmentation in the region without adequate structural adjustment may therefore present a significant challenge for the longterm sustainability of the cattle industry. This therefore supports the need for the development of appropriate rural area strategy that focuses on efficient land use patterns among dairy farmers.

\subsection{Limitations}

It is important to stress that, like other studies, this study is not without its limitations. Whilst every effort was made to ensure that herd types were appropriately classified based on production practices, the potential for classification bias still remains. This is most likely to impact non-dairy herds, however given that the general findings were similar for all non-dairy herd types, the impact on the conclusions are minimal. Another limitation of the study is that it is impossible to know which land parcels are actually utilised for cattle grazing. Whilst we have some understanding of this at a small scale (Campbell et al., 2020a), it is not possible to assess whether these findings can be generalised to the entirety of NI. Undoubtedly, there are expansive farms in this study which utilise only a small component of their holdings for cattle grazing. Furthermore, it is not possible to assess what land has been rented out as conacre. However, given the lack of evidence for changes in the number of land parcels at the farm level through time, we hypothesise that the effects of conare on the results are minimal. Notwithstanding these limitations, this study make an important contribution to the land fragmentation literature. Further research is needed to explore ways by which farmland fragmentation can be reduced and the role of land rental 
market in farmland fragmentation. Future studies may also include exploring the structural causes underlying the process of farmland fragmentation.

\section{Conclusions}

An explicit understanding of the degree of farmland fragmentation is essential to promote sustainable utilisation of farmlands by optimizing farmland use structure, and improving land use efficiency. In this study, using the LPIS data base, we analysed the extent of farmland fragmentation for cattle enterprises in Northern Ireland. Our study show that notable differences exist in the degree of farmland fragmentation across the various cattle enterprise studied. Specifically, we found that dairy farms are more fragmented when compared to the other cattle enterprise. This has significant implication for land use policy development. The information will be useful in designing appropriate policy to promote economic viability of the rural areas through maintaining efficient use and distribution of farmlands to ensure farm productivity improvement as well as maintain biodiversity and habitat heterogeneity in the rural areas.

Declaration of interest: Declarations of interest: none

Author Contributions: Georgina Milne - Methodology, Formal analysis, Visualization, Writing - Original Draft, Writing - Review \& Editing, Project administration

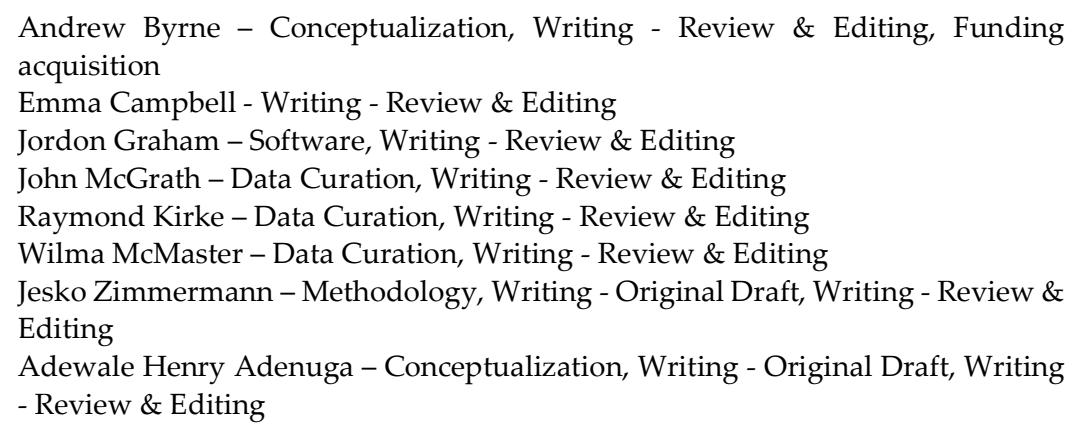

Funding source: This work was supported by the Department of Agriculture, Environment and Rural Affairs (DAERA), and was fully funded under grant 18/3/02 (48258) - FaRTHEr: Fragmentation As a Risk factor for TB in cattle Herds: impacts on Eradicatio

\section{References}

Abernethy, D.A., Denny, G.O., Menzies, F.D., McGuckian, P., Honhold, N., Roberts, A.R., 2006. The Northern Ireland programme for the control and eradication of Mycobacterium bovis. Veterinary Microbiology 112, 231-237.

Abernethy, D.A., Moscard-Costello, J., Dickson, E., Harwood, R., Burns, K., McKillop, E., McDowell, S., Pfeiffer, D.U., 2011. Epidemiology and management of a bovine brucellosis cluster in Northern Ireland. Preventive veterinary medicine 98, 223-229.

Adenuga, A.H., Davis, J., Hutchinson, G., Donnellan, T., Patton, M., 2018. Estimation and determinants of phosphorus balance and use efficiency of dairy farms in Northern Ireland: A within and between farm random effects analysis. Agricultural Systems 164, 11-19.

Adenuga, A.H., Davis, J., Hutchinson, G., Patton, M., Donnellan, T., 2020. Analysis of the effect of alternative agri-environmental policy instruments on production performance and nitrogen surplus of representative dairy farms. Agricultural Systems 184, 102889.

Agresti, A., 2007. An Introduction to Categorical Data Analysis. Wiley-Interscience Hoboken, NJ.

Alexander, D.J., 1963. A Note of the Conacre system in Northern Ireland. Journal of Agricultural Economics $15,471-475$. 
Allen, A., Breadon, E., Byrne, A., Mallon, T., Skuce, R., Groussaud, P., Dainty, A., Graham, J., Jones, K., Pollock, L., Whatmore, A., 2015. Molecular Epidemiology of Brucella abortus in Northern Ireland1991 to 2012. PLOS ONE 10, e0136721.

Allen, M., 2016. Overview of the beef sector/suckler cow industry in Northern Ireland, Research and Information Service Briefing Paper. Northern Ireland Assembly.

Asiama, K.O., Bennett, R., Zevenbergen, J., 2017. Land Consolidation for Sub-Saharan Africa's Customary Lands-The Need for Responsible Approaches. Am. J. Rural Dev 5, 39-45.

Barrett, D.J., More, S.J., Graham, D.A., O'Flaherty, J., Doherty, M.L., Gunn, H.M., 2011. Considerations on BVD eradication for the Irish livestock industry. Irish Veterinary Journal 64, 12.

Barrington, M.J., Ilbery, B.W., 1987. Farm fragmentation: a case study from Coventry's urban fringe. Geoforum 18, 237-245.

Bartolini, F., Viaggi, D., 2013. The common agricultural policy and the determinants of changes in EU farm size. Land Use Policy 31, 126-135.

Bentley, J.W., 1987. Economic and ecological approaches to land fragmentation: In defense of a muchmaligned phenomenon. Annual Review of Anthropology 16, 31-67.

Binns, S.B.O., Binns, B.O., 1950. The consolidation of fragmented agricultural holdings. Food and Agriculture Organization of the United Nations.

Bivand, R., Keitt, T., Pebesma, E., Rowlingson, B., 2010. rgdal: Bindings for the Geospatial Data Abstraction Library.

Bivand, R., Rundel, C., 2017. rgeos: Interface to Geometry Engine - Open Source ('GEOS').

Brown, D.G., 2003. Land use and forest cover on private parcels in the Upper Midwest USA, 1970 to 1990. Landscape ecology 18, 777-790.

Brown, E., Marshall, A.H., Mitchell, H.J., Byrne, A.W., 2019. Cattle movements in Northern Ireland form a robust network: implications for disease management. Preventive veterinary medicine 170, 104740.

Byrne, A.W., Barrett, D., Breslin, P., Madden, J.M., Keeffe, J., Ryan, E., 2020. Bovine Tuberculosis (Mycobacterium bovis) outbreak duration in cattle herds in Ireland: A retrospective observational study. Pathogens 9.

Campbell, E.L., Byrne, A.W., Menzies, F.D., Milne, G., McBride, K.R., McCormick, C.M., Scantlebury, D.M., Reid, N., 2020a. Quantifying intraherd cattle movement metrics: Implications for disease transmission risk. Preventive veterinary medicine, 105203.

Campbell, E.L., Menzies, F.D., Byrne, A.W., Porter, S., McCormick, C.M., McBride, K.R., Scantlebury, D.M., Reid, N., 2020b. Grazing cattle exposure to neighbouring herds and badgers in relation to bovine tuberculosis risk. Research in Veterinary Science.

Cheng, L., Xia, N., Jiang, P., Zhong, L., Pian, Y., Duan, Y., Huang, Q., Li, M., 2015. Analysis of farmland fragmentation in China Modernization Demonstration Zone since "Reform and Openness": a case study of South Jiangsu Province. Scientific Reports 5, 11797.

Cholo, T.C., Fleskens, L., Sietz, D., Peerlings, J., 2019. Land fragmentation, climate change adaptation, and food security in the Gamo Highlands of Ethiopia. Agricultural Economics 50, 39-49.

Ciaian, P., Guri, F., Rajcaniova, M., Drabik, D., y Paloma, S.G., 2018. Land fragmentation and production diversification: A case study from rural Albania. Land use policy 76, 589-599.

Constantin, C., Luminița, C., Vasile, A.J., 2017. Land grabbing: A review of extent and possible consequences in Romania. Land Use Policy 62, 143-150.

Cungu, A., Swinnen, J.F., 1999. Albania's radical agrarian reform. Economic development and cultural change 47, 605-619.

DAERA, 2017. EU Farm Structure Survey 2016 Northern Ireland. In: CAP Policy, E.a.S.D. (Ed.) Department of Agriculture, Environment and Rural Affairs, UK.

DAERA, 2020. Final Results of the June Agricultural Census 2019. Statistics and Analytical Services Branch, Policy, Economics and Statistics Division Belfast.

Davis, J., Caskie, P., Wallace, M., 2009. Economics of farmer early retirement policy. Applied Economics 41, 35-43.

de Vries, W.T., 2016. Post disaster consolidation of land, memory and identity. In, FIG Working Week, 12.

Demetriou, D., 2014. Land Fragmentation: The development of an integrated planning and decision support system (IPDSS) for land consolidation. Springer, 11-37.

Denny, G.O., Wilesmith, J.W., 1999. Bovine tuberculosis in Northern Ireland: case-control study of herd risk factors. The Veterinary Record 144, 310.

Durr, P.A., Froggatt, A.E.A., 2002. How best to geo-reference farms?: A case study from Cornwall, England. Preventive veterinary medicine 56, 51-62.

EC, 2013. Eradication programme for Bovine Tuberculosis - United Kingdom. Programmes for the eradication, control and monitoring of certain animal diseases and zoonoses. Commission européenne, B-1049 Bruxelles.

Economics, O., 2013. Regional price disparities in dead weight cattle: Understanding the NI / GB Price Differential. Livestock and Meat Commission 
Edwards, C.J.W., 1978. The effects of changing farm size upon levels of farm fragmentation: A Somerset case study. Journal of Agricultural Economics 29, 143-154.

Gomes, E., Banos, A., Abrantes, P., Rocha, J., Kristensen, S.B.P., Busck, A., 2019. Agricultural land fragmentation analysis in a peri-urban context: From the past into the future. Ecological Indicators 97, 380-388.

Hijmans, R.J., Etten, J.v., 2012. raster: Geographic analysis and modeling with raster data.

Hothorn, T., Hornik, K., van de Wiel, M.A., Zeileis, A., 2006. A lego system for conditional inference. The American Statistician 60, 257-263.

Houston, R., 2001. A computerised database system for bovine traceability. Revue Scientifique et TechniqueOffice International des Epizooties 20, 652.

Igbozurike, M.U., 1974. Land tenure relations, social relations and the analysis of spatial discontinuity. Area $6,132-136$.

Jack, C., Miller, A.C., Ashfield, A., Anderson, D., 2019. New entrants and succession into farming: A Northern Ireland perspective. International Journal of Agricultural Management 8, 56-64.

King, R., Burton, S., 1982. Land Fragmentation: Notes on a fundamental rural spatial problem. Progress in Human Geography 6, 475-494.

Knippenberg, E., Jolliffe, D., Hoddinott, J., 2018. Land fragmentation and food insecurity in Ethiopia. The World Bank.

LaPierre, S., Germain, R.H., 2005. Forestland parcelization in the New York City watershed. Journal of Forestry 103, 139-145.

Magee, S.A.E., 2002. Farmers and farm families in NI. DAERA, Economics \& Statistics Division.

McCann, M., Colhoun, K., 2007. The red meat industry taskforce. Northern Ireland Assembly, Belfast.

Milne, G., Allen, A., Graham, J., Kirke, R., McCormick, C., Presho, E., Skuce, R., Byrne, A.W., 2020. Mycobacterium bovis population structure in cattle and local badgers: Co-localisation and variation by farm type. Pathogens 9, 592.

NIAO, 2018. The control of Bovine Tuberculosis in Northern Ireland. Northern Ireland Audit Office, Belfast.

Ntihinyurwa, P.D., de Vries, W.T., 2020. Farmland fragmentation and defragmentation nexus: Scoping the causes, impacts, and the conditions determining its management decisions. Ecological Indicators 119 , 106828 .

Ntihinyurwa, P.D., de Vries, W.T., Chigbu, U.E., Dukwiyimpuhwe, P.A., 2019. The positive impacts of farm land fragmentation in Rwanda. Land Use Policy 81, 565-581.

O'Hagan, M.J.H., Matthews, D.I., Laird, C., McDowell, S.W.J., 2016. Herd-level risk factors for bovine tuberculosis and adoption of related biosecurity measures in Northern Ireland: A case-control study. The Veterinary Journal 213, 26-32.

O’Donnell, S., 2013. Farm fragmentation in Irish dairying - Overcoming and sdapting to it. Nuffield Ireland Farming Scholarships.

Olagunju, K.O., Angioloni, S., Wu, Z., 2019. Who really benefits from single payment scheme (SPS) under convergence of payments? Micro evidence from Northern Ireland.

Palisson, A., Courcoul, A., Durand, B., 2017. Analysis of the spatial organization of pastures as a contact network: Implications for potential disease spread and biosecurity in Livestock, France, 2010. PLOS ONE 12, e0169881.

Postek, P., Leń, P., Stręk, Ż., 2019. The proposed indicator of fragmentation of agricultural land. Ecological Indicators 103, 581-588.

Rahman, S., Rahman, M., 2009. Impact of land fragmentation and resource ownership on productivity and efficiency: The case of rice producers in Bangladesh. Land Use Policy 26, 95-103.

Rowland, C.S., Morton, R.D., Carrasco, L., McShane, G., O'Neil, A.W., Wood, C.M., 2017. Land Cover Map 2015 (vector, N. Ireland). NERC Environmental Information Data Centre.

Sabates-Wheeler, R., 2002. Consolidation initiatives after land reform: responses to multiple dimensions of land fragmentation in Eastern European agriculture. Journal of International Development 14, 1005.

Sherlund, S., Barrett, C., Adesina, A.A., 2002. Smallholder technical efficiency: Controlling for environmental production conditions. Journal of Development Economics 69, 16.

Sklenicka, P., Janovska, V., Salek, M., Vlasak, J., Molnarova, K., 2014. The Farmland Rental Paradox: extreme land ownership fragmentation as a new form of land degradation. Land use policy 38, 587-593.

Sklenicka, P., Salek, M., 2008. Ownership and soil quality as sources of agricultural land fragmentation in highly fragmented ownership patterns. Landscape Ecology 23, 299-311.

Sundqvist, P., Andersson, L., 2007. A study of the impacts of land fragmentation on agricultural productivity in Northern Vietnam. Nationalekonomiska institutionen.

Tan, S., 2005. Land fragmentation and rice production : a case study of small farms in Jiangxi Province, P.R. China. Wageningen University.

R Core Team, 2013. R: A Language and Environment for Statistical Computing. R Foundation for Statistical Computing Vienna, Austria.

van Dijk, T., 2003. Scenarios of Central European land fragmentation. Land Use Policy 20, 149-158.

Wickham, H., 2009. ggplot2: Elegant Graphics for Data Analysis. Springer-Verlag New York. 
Zimmermann, J., Fealy, R., Lydon, K., Mockler, E., O'Brien, P., Packham, I., Smith, G., Green, S., 2016. The Irish Land-Parcels Identification System (LPIS)-Experiences in ongoing and recent environmental research and land cover mapping. Biology and Environment: Proceedings of the Royal Irish Academy 116B, 1. 